\title{
A EXPERIÊNCIA URBANA E APROPRIAÇÃO ESPACIAL A PARTIR DO JOGO DE REALIDADE AUMENTADA (ARG) INGRESS
}

\author{
Breno Maciel Souza Reis ${ }^{1}$
}

\section{Introdução}

Os sujeitos sempre estabeleceram uma relação com o jogo como um modo de estar no mundo e de contato com as coisas, ou seja, uma mediação (Buytendijk, 1977; Caillois, 1990; Gadamer, 1997; Huizinga, 2008), diretamente relacionada ao próprio sentido de temporalidade que a coletividade humana possui em determinado momento histórico - e indicando como se estrutura o pensamento e como entendemos a realidade. Longe de ser um processo exterior, ele possui imbricações que se enraízam na concepção que temos sobre nós mesmos e sobre o que nos cercam, constituindo assim mais do que uma atividade de mera diversão ou ausente de seriedade, mas um elemento de apropriação e construção da realidade; ou seja, o jogo é parte fundamental da vida humana e da construção cultural advinda da nossa experiência de mundo (Teixeira, 2005: 467).

Assim, as relações que estabelecemos com o jogo hoje e o seu lugar na sociedade contemporânea refletem o modo como vivemos e interpretamos o mundo, uma vez que os mesmos se desenvolvem em uma dada configuração momentânea, social, tecnológica e cultural. Especialmente no caso deste trabalho, observamos a ubiquidade de tecnologias computacionais móveis constantemente conectados, assumindo também formas lúdicas e vinculadas ao espaço físico das cidades - alterando não apenas práticas espaciais individuais e coletivas, mas também sobrepondo distintas camadas informacionais e também simbólicas, a partir da caminhada dos sujeitos e da ressignificação desses mesmos espaços. Se em outros períodos históricos a ocorrência do jogo era potencialmente distinguível das demais atividades cotidianas, hoje o seu caráter pervasivo parece-nos ainda mais evidente, porém não claramente reconhecível, haja vista que ele passa a abranger as mais diversas atividades da vida ordinária.

Isso dito, percebemos na atualidade um deslocamento no tocante à própria experiência urbana, sabendo da existência de aparatos tecnológicos digitais de conexão contínua à rede e que se relacionam com o ambiente de maneira locativa (ou seja, contextualmente geolocalizada), se configurando como mediadores entre as experiências

\footnotetext{
${ }^{1}$ Universidade Federal do Rio Grande do Sul, Brasil.
} 
subjetivas que são desenvolvidas no contexto espacial, social e informacional das cidades. Tomando como horizonte a própria complexidade inerente à matéria, apontaremos algumas questões relacionadas à apropriação de sistemas lúdicos com vistas à sua utilização por sujeitos portando aparatos portáteis, como possível modificador da experiência urbana mediada tecnologicamente.

Nos ancoraremos na abordagem antropológica etnográfica na cidade, em consonância com o que defendem Rocha e Eckert (2013a;2013b;2013c), que consideram que a investigação sobre os modos de vida nas cidades deve levar em conta não só o aspecto urbano formal e planejado; mas também a multiplicidade de usos e apropriações imprevistas - e, por muitas vezes, subversivas - do espaço urbano. Ou seja, considerar que a rua é, desde sempre, um espaço de interação social, locus por excelência de disputas territoriais, simbólicas, materiais e no qual se manifestam e se formam trajetórias de sujeitos e grupos.

Para tanto, serão expostas reflexões que advém primordialmente da nossa utilização do jogo, as impressões e experiências provenientes dessa inserção. Assim, esse artigo também empreende um exercício de afastamento em relação à nossa própria experiência no contexto da cidade de Porto Alegre, onde residimos, mas da qual não somos naturais.

A esse respeito, destacam Rocha e Eckert (2013b, p. 22) que a etnografia de rua é um exercício de “(...) deslocamento em sua própria cidade, o que significa dizer [...] que ela afirma uma preocupação com a pesquisa antropológica a partir do paradigma estético na interpretação das formas de vida social na cidade". Dessa forma, procuramos nos inserir na cosmologia própria do jogo em questão, buscando, por meio das nossas caminhadas (tanto nos trajetos cotidianos, quanto naqueles realizados com propósitos específicos e voltados à exploração citadina lúdica que o jogo exige), capturar e questionar essa ambiência, e perceber alterações na forma como nos apropriamos da mesma - ou como entende Certeau (1998), como se dão as nossas estratégias e táticas de (des)construção narrativa a partir dos passos e deslocamentos diários.

\section{Delimitando a questão: o jogo e seu caráter pervasivo como possibilidade de apropriação da cidade e ressignificação do espaço}

Se tomarmos como verdadeira a premissa que diversos autores dedicados ao estudo do jogo corroboram, de que o fenômeno foi, e ainda é, de fundamental importância para a nossa evolução e para a constituição de sociedades humanas - independente do grau de 
complexidade e organização normativa que possuem - podemos facilmente perceber que, desde os primórdios, o homem se utilizou do jogo como instrumento de compartilhamento e construção simbólica sobre o mundo. Para Buytendijk (1977), uma característica intrínseca ao que aqui chamamos jogo é o fato de ele ser um mediador entre o homem e as coisas; ou seja, sob tal perspectiva, o jogo consiste em um modo de inserção no mundo. Assim, devido ao caráter simbólico inerente ao jogo, o pensador entende que ele é um dos elementos que nos permitem diferenciar-nos dos animais - assim, o fenômeno do qual falamos, mais do que mera diversão ou recreação, se configura como uma experiência emancipatória humana, uma vez que ele se presta como transformador das relações que os sujeitos estabelecem consigo mesmos, com os outros e com o mundo.

Huizinga (2008), um dos principais teóricos e considerado o fundador do campo hoje conhecido como game studies, entende que a existência do jogo entre nós e o seu caráter simbólico representou, desde sempre, um papel fundamental na organização e construção cultural humana. Assim, ele entende essa relação a partir de uma tríade ontológica, propondo assim que o homem lúdico (Homo ludens) foi tão importante quanto a nossa capacidade de raciocinar e pensar a realidade (Homo sapiens) e de criar, manipular e interagir com a natureza, modificando-a (Homo faber). Para o autor, inclusive, a linguagem é uma tecnologia humana essencialmente lúdica, considerando também a sua ocorrência como um jogo - o que é corroborado por filósofos da linguagem, como Wittgenstein (1989).

Destarte, pelo viés que consideramos aqui, o jogo se presta como um reflexo da sociedade na qual se desenvolve, conforme assinala McLuhan (2007); entretanto, poderíamos acrescentar que, muito mais do que apenas prover indícios do modus vivendi particular ou funcionar como extensões de uma sociedade, como afirma o autor, o jogo também atua diretamente na definição de conceitos, regras, do que é válido ou não na vida social. Nesse sentido, ele se articula com as contingências subjetivas, sociais, espaciais e culturais nas quais se desenvolve, inaugurando uma esfera própria de existência que possui um caráter simbólico que circunscreve - e delimita - a própria experiência lúdica, por ser reconhecidamente distinto da vida ordinária dos seus praticantes.

Além disso, é interessante observar também como, para Simmel (1983), os processos dialógicos inerentes a toda interação social carregam em sua essência um aspecto lúdico. Ao dissertar a respeito, o autor conclui que o jogo está, desde sempre e de 
forma íntima, relacionado à própria noção de sociedade - e especificamente no que nos interessa nesse trabalho, as dinâmicas de conflito e competição que se articulam na narrativa cosmológica do Ingress, conforme será exposto. Para o sociólogo, “a conexão entre jogo e sociabilidade explica porque esta deve abranger todos os fenômenos que já por si mesmos podem ser considerados formas sociológicas lúdicas. Isto se refere acima de tudo a jogos propriamente ditos que, na sociabilidade de todos os tempos, desempenhou um papel notável" (1983: 174). Ainda acrescenta que "o sentido mais profundo, o duplo sentido de 'jogo social' é que o jogo não só é praticado em uma sociedade (como seu meio exterior), mas que, com ele, as pessoas 'jogam' realmente 'sociedade"' (1983: 174).

Isso nos permite problematizar tal ideia clássica da separação bem definida entre o jogo e a vida cotidiana, a partir da ubiquidade das tecnologias digitais móveis de Comunicação e Informação na contemporaneidade, entendendo que passamos a experimentar o fenômeno do jogo em momentos nos quais não reconhecemos sua ocorrência de maneira clara ou imediata. Se antes o jogo pressupunha um certo ritual para que ocorresse (por exemplo, para utilizar um console de videogame, é necessário que o jogador decida realizar naquele momento a atividade em questão; que ligue o aparelho e também a televisão à qual o videogame está conectado, que pegue os controles ou ative outros dispositivos, como sensores de leitura de movimentos corporais), hoje, dado o cenário ubíquo e o horizonte de permanência cada vez mais invisível das tecnologias infocomunicacionais na vida humana, estamos envolvidos em atividades lúdicas das quais frequentemente não damos conta de sua ocorrência.

Com efeito, um tipo de jogo específico emerge desse contexto, que é designado por Lemos (2010) pela expressão jogos móveis locativos (JML), ou seja, “(...) jogos urbanos que utilizam tecnologias e serviços baseados em localização nos quais o lugar é parte integrante das regras e das ações do jogo". Podemos, analogamente, dizer que eles transformam a configuração física das cidades em um tabuleiro de jogo, no qual os usuários se movimentam, tanto com o objetivo lúdico explícito, quanto na realização de suas tarefas cotidianas; essa é, aliás, uma diferença fundamental que admite a pervasividade do jogo, nesse caso. Mäyrä (2008) entende, assim, que os jogos desse tipo ultrapassam o ambiente tradicional característico dos consoles de videogame e, deliberadamente, misturam a esfera do jogo com a vida ordinária, criando interseções entre essas instâncias. O fenômeno passa, cada vez mais, a abarcar aspectos que até então 
não eram considerados como jogo - e, inclusive, aqueles que socialmente são considerados sua antítese, como o trabalho e a educação escolar - os quais confirmam sua presença difusa e seu caráter medial.

Em relação aos JML podemos ainda acrescentar as considerações de Hjorth (2011), que entende como fundamentais as interseções entre o espaço e a mobilidade informacional proporcionada por artefatos tecnológicos digitais, afirmando que, justamente por colocar em sinergia espaços on-line e off-line, eles podem oferecer novas formas de experienciar a realidade, ou simplesmente o lugar no qual o sujeito se encontra. Para a autora, a possibilidade de interação em rede e do uso do espaço citadino como elemento lúdico oferecem uma oportunidade de transformar os modos como os sujeitos se apropriam e atribuem sentido aos mesmos. Assim, ela acredita que a mobilidade e tecnologias em rede não apenas alteram como nós entendemos o espaço na vida cotidiana, mas também nos lembram que o lugar é mais que somente a sua localização física e/ou geográfica. Com mais importância, ele é construído através do acúmulo constante de histórias, memórias e práticas sociais.

Nesse sentido, essas formas de habitação do espaço admitem a sua transformação em ambientes essencialmente lúdicos, ou seja, as cidades contemporâneas como espaços de fluxos que assumem características de jogo pela sua transmutação, a partir da qual os próprios sujeitos são os jogadores se movimentando pelos locais - mas não mais apenas em momentos específicos nos quais o círculo mágico do jogo, conforme sugere Huizinga (2008) encontra-se em evidente existência. A característica pervasiva do jogo - e que, reafirmamos, lhe é própria -, encontra nas tecnologias móveis de comunicação ubíquas potencializadores que fazem com que sua existência se dê de forma cada vez mais permanente e invisível, imbricada em meio à própria vida cotidiana.

Assim como a própria rede e a tecnologia se infiltra no corpo social e é por ele incorporada, derivando apropriações na forma de práticas sociais e culturais, o jogo também encontra um vetor que potencializa a diluição das fronteiras entre o jogo e não jogo, o trabalho e o lúdico. A cidade, que passou a representar durante um longo período, o enraizamento do sujeito em detrimento da pulsão da errância ou do nomadismo, como defende Maffesoli (2001); na qual era permitido ao sujeito se apropriar apenas parcialmente de suas camadas de sentido que sempre existiram, porém, eram restritas a locais ou grupos específicos, encontra, na sua transformação em ambiente lúdico em rede, 
possibilidades de ampliação de suas capacidades de comportar e dar visibilidade à multiplicidade de sentidos que sempre lhe foi característica.

Neste sentido, especificamente no caso dessas manifestações culturais contemporâneas, o círculo mágico do qual falam Huizinga (2008) e Caillois (1990) é expandido de várias formas: o jogo não ocorre mais em tempos e espaços bem definidos, e os seus participantes não são determinados. Nesse sentido, como diagnosticam Montola, Stenros e Waern (2009), os jogos nesse contexto permeiam, se desdobram e embaçam os seus limites tradicionais, por expandir o ambiente do jogo a partir de três perspectivas: a temporal, ou seja, seja o fato de estarmos cada vez mais imersos em atividades lúdicas; a espacial, que, conforme dissemos, remete à possibilidade de jogar em variados lugares, em condições de deslocamento ou a dispensabilidade de consoles fixos ou limitados a ambientes específicos; e a social, que, enquanto fator resultante das anteriores, trata-se da ampliação do número de possíveis jogadores em todos os lugares e a todo instante, em seus trajetos diários, inclusive utilizando o espaço citadino como o ambiente no qual a história do jogo se desenrola.

\section{As cibercidades e mídias locativas como pressuposto para a existência dos JML}

A condição de mobilidade da informação proporcionada pelas tecnologias de conexão contínua (Santaella, 2007) e a estrutura que foi instalada no espaço urbano para dar conta das mesmas, provocaram um novo paradigma ao já recente campo de estudo da cibercultura, inserindo novas configurações tanto comunicacionais e informacionais, quanto arquitetônicas, urbanísticas, sociais, bem como também artísticas e estéticas, uma vez que foi possível portar para as ruas das cidades tecnologias antes fixas e limitadas a ambientes fechados, como empresas e residências. O ciberespaço, assim, passou a estar em todos os lugares, alterando também as paisagens e como vivenciamos o mundo físico, agora mediados por dispositivos digitais conectados em rede de maneira ubíqua.

A esse entrecruzamento composto pelo espaço urbano em sua materialidade (praças, avenidas, monumentos históricos, edifícios, etc.), a infraestrutura tecnológica necessária - como antenas, cabos, redes sem fio de telefonia e de dados, além dos próprios dispositivos em sua fisicalidade - somados aos sujeitos que transitam e portam consigo esses aparatos, Lemos (2004) denomina como cibercidade ou cidade-ciborgue. 
Importante lembrar que, para o autor, a própria cidade é uma construção cultural e artificial humana repleta de sentido - ou seja, um artefato, desenvolvido e em relação direta com as configurações tecnosociais vigentes em um dado período histórico.

As cibercidades seriam assim a medida de nossa época, palimpsestos nos quais se inscrevem discursos e se proferem enunciados, tanto através da interferência dos sujeitos fisicamente, quanto através da esfera informacional e móvel que se sobrepõe a ela, modificando nossa vivência do espaço urbano - basta pensarmos em tecnologias de geolocalização via satélite, ou GPS, as quais conseguem rastrear a localização exata de alguém em coordenadas geográficas e fornecer uma experiência ampliada do espaço físico circundante. Dessa forma, funcionam também como navegadores urbanos, conectando dispositivos, satélites e redes sem fio com as ruas das cidades, tomando agora novas formas e moldando a polis contemporânea por meio da junção da mesma com o ambiente virtual das redes telemáticas (Lemos, 2004) - concretizando a existência das mídias locativas, ligadas diretamente ao contexto espacial, informacional e social na qual estão sendo utilizadas.

O termo mídia locativa foi cunhado por Karlis Kalnins para designar o uso de serviços em rede baseados em geolocalização (location-based services, ou LBS); entretanto, as mídias locativas já existiam analogicamente, na forma de cartazes, mapas, placas de trânsito e anúncios expostos no espaço urbano. Em relação às mídias locativas digitais, parece-nos que o fator fundamental de diferenciação das mesmas é o fato de que elas estão, eletronicamente e de maneira ubíqua, organizadas no ciberespaço na forma de metadados e contextualmente relacionadas, pois se constituem como tecnologias sensíveis ao ambiente, permitindo acesso e armazenamento de informações em bases de dados de serviços que se propõe a agrupar e exibir nas telas de variados dispositivos essas informações.

Sem dúvida, se locomover pela cidade carregando consigo um dispositivo conectado e exibindo constantemente informações sobre ela impacta no modo como direcionamos nosso olhar para a mesma. Ao mesmo tempo em que proporcionam uma ampliação das nossas capacidades cognitivas e perceptivas, representam também uma transposição das mesmas para a exterioridade de nossos corpos, as quais retornam na forma de pacotes de informação e que são interpretados não por nós, mas pelo dispositivo receptor e exibidas nas telas dos mesmos. 
A esse respeito, sabemos que os instrumentos e tecnologias que utilizamos modificam nossa visão sobre o mundo e nosso entendimento sobre o ambiente que nos cercam, promovendo novas dinâmicas de interação com o mesmo e nos modos como o habitamos. Armazenadas em grandes repositórios de informação e transformadas em práticas sociais, elas penetram de forma profunda no cotidiano até quase se tornarem invisíveis, dada sua característica pervasiva, integrando de forma definitiva a camada virtual, e o mundo físico, em processos nos quais não se reconhece de imediato o início de um e o fim do outro (Weiser, 1991).

Podemos aqui retomar as considerações de Meyrowitz, que em No Sense of Place (1985), entende os novos contextos midiáticos como potencializadores de transformações nas interações sociais - desde os já bastante estudados meios massivos, como a televisão, rádio e impressos, até mais recentemente os digitais e globalmente conectados. Considerando que o espaço também exerce grande influência na sociabilidade entre os indivíduos, entendemos que o paradigma se encontra justamente do momento em que percebemos a informatização do território e a potencialização da construção simbólica do mesmo em rede, ou seja, o que Certeau (1998) chama de retóricas ambulatórias, agora na forma de rastros informacionais que compõe as histórias e o registro dos lugares, transformando a cidade em “(...) redes comunicativas, florestas de cabos, e na transformação do sujeito, 'atraído' e estendido nas esferas eletrônicas e nas formas de relações metageográficas" em desbravador desse novo território flutuante" (Di Felice, 2009: 160). Lemos, inclusive, sugere que agora, temos um novo sentido do lugar (new sense of place), um território informacional, “(...) onde relações comunicacionais se dão diretamente com lugares e objetos do espaço urbano, potencializando apropriação e ressignificação" (2010: 2).

\section{A etnografia de rua como exercício de deslocamento em relação ao Ingress}

Isso dito, um dos questionamentos que norteiam esse trabalho são os possíveis desdobramentos que tais expansões do jogo acarretam no tocante à apropriação e experiência citadina em um contexto de conexões locativas a partir de um cenário lúdico. Especificamente no caso deste trabalho, observamos a cidade, espaço em certa medida organizado e normatizado segundo regras de planejamento mais ou menos estruturadas e com usos também previstos, mas que assume outros sentidos e é ressignificada a partir 
das caminhadas dos sujeitos, da forma como ela é vivenciada - ou, como sugere Certeau (1998), os sujeitos, em seus trajetos e a partir das narrativas cotidianas escritas pelos seus passos, transformam em outras coisas cada elemento disponível no espaço urbano.

Narrar a cidade nesse contexto significa essencialmente desvendar os seus usos, os enredos que nela são inscritos, entendendo-a como locus primordial onde se dão relações sociais, ou seja, “(...) um arranjo espaço-temporal onde a vida social se desenrola nas suas mais diversas formas" (Rocha; Eckert, 2013c: 13). É nas ruas, e através das sutis falas dos passos, que apreendemos os modos de vida em um espaço contraditório por excelência, por comportar os mais diversos e inusitados usos; possuidora de diversas cosmologias, a cidade coexiste com diversas faces de si mesma, construídas em temposespaços distintos e sobrepostos, nos quais vão sendo tecidas camadas de sentido. Ela é, assim, o "(...) lugar imaginado e vivido, a rua em que moramos ou a rua que frequentamos assiduamente em nossas tarefas diárias, as ruas que falam da cidade, as ruas onde depositamos nossos sonhos e involuntariamente recordamos e desejamos" (Rocha; Eckert, 2013c: 13).

Um aspecto a ser destacado na fala das autoras e que nos leva ao próprio objeto que aqui tomamos para análise é característica do Ingress de estimular o jogador a praticar a cidade a partir de uma narrativa cosmológica que é própria do jogo: a descoberta de uma forma de energia denominada Exotic Matter (Matéria Exótica, ou XM) que emana de alguns pontos da cidade e que pode tanto ser manipulada para levar a Humanidade a um novo estágio de "consciência", quanto ameaçar a nossa própria existência, a liberdade e o pensamento. A partir dessa premissa, duas facções se formam e disputam o controle sobre esses locais nos quais a XM se concentra (chamados portais): os Iluminados (Enlightened) e a Resistência (Resistance).

Assim, para que fosse possível adentrar no universo do Ingress, procedemos na instalação do aplicativo em um smartphone com sistema operacional Android e realizamos o cadastro, seguido da escolha de um pseudônimo que identifica os jogadores no sistema - não é necessário fornecer o nome real nem uma fotografia, embora seja possível customizar um emblema com formas e cores fornecidas pelo aplicativo. Como parte da narrativa do jogo consiste em transformar o jogador em um "agente" de uma das facções (inclusive os jogadores se chamam assim), o anonimato é assegurado, sendo possível apenas, ao visualizar o perfil de um jogador, ter acesso a dados relativos à sua participação, como nível, medalhas obtidas (badges), pontuação e demais informações. 
Ao jogar na e com a cidade, os jogadores se apropriam do espaço físico distintamente do que fariam em outra situação: uma praça não é somente uma praça, mas significa para os mesmos outra coisa: um portal, um ponto de encontro de jogadores de uma facção, um território de disputa simbólica, cujo sentido é estritamente singular - ou seja, experiências são produzidas e contextos articulados, os quais são tecidos à narrativa lúdica, enriquecendo o universo próprio do jogo, criando usos imprevistos ou, como ainda defende Certeau (1998), proporcionando práticas inventivas, criativas, costumes e estratégias particulares. Ou ainda, como acreditam Rocha e Eckert (2013b: 14), "são essas ações, ou práticas cotidianas, que conferem as feições particulares das ruas, dos territórios urbanos, dos espaços vividos coletivamente na cidade".

Tendo isso exposto, uma vez instalado o aplicativo e escolhida a facção à qual nos vincularíamos, nos tornamos um "agente" do Ingress em Porto Alegre. Esse processo, que Kozinets (2010) chama de entreé cultural, consiste em adentrar o universo a ser estudado através da imersão do pesquisador no objeto, que ocorreu, no caso em questão, com a utilização do Ingress nas situações mais variadas: tanto em trajetos cotidianos, nos percursos habituais, quanto também com saídas a campo especificamente com o propósito do jogo. Hine (2000) entende essa imersão como fundamental na pesquisa etnográfica, pois requer do investigador uma postura de comprometimento e de engajamento em relação ao objeto e com os sujeitos que o constituem. Ou seja, é necessário que o pesquisador adentre no ambiente estudado e que atente às redes de relações que emergem tanto entre os sujeitos a partir das interações que estabelecem entre si, quanto com o próprio ambiente, os artefatos tecnológicos e com o contexto espacial, social e cultural no qual se inserem.

Esse trabalho constitui também um exercício de deslocamento no tocante à própria experiência urbana que possuímos de Porto Alegre, cidade onde se desenvolve a pesquisa em questão. Para isso, tomamos as considerações de Simmel (1983) em seu texto sobre o estrangeiro, buscando nos tornar estranhos no espaço ao qual estamos habituados e que percorremos diariamente. Dizemos isso porque sabemos que com o dia a dia certas particularidades da cidade, seus usos e habitantes, se tornam "transparentes" ao filtro invisível que o cotidiano impõe e, muitas vezes, nos desafia a olhar a cidade sob outra perspectiva: a de sua constante construção e destruição criativa por meio das práticas que nela se dão. Assim, aponta Simmel (1983: 184) que 
O estrangeiro não está submetido a componentes nem a tendências peculiares do grupo e, em consequência disso, aproxima-se com a atitude específica de "objetividade". Mas a objetividade não envolve simplesmente passividade e afastamento; é uma estrutura particular composta de distância e proximidade, indiferença e envolvimento. [...] Objetividade não significa de maneira alguma nãoparticipação (que geralmente exclui tanto a interação subjetiva quanto a objetiva), mas um tipo específico e positiva de participação (...).

Na busca pela delimitação de um campo para a pesquisa em questão, nos apoiamos em Fragoso, Recuero e Amaral (2011: 182) que, com base em Hine (2009), defendem a inseparabilidade do mesmo da vida cotidiana, tanto do pesquisador, quanto do grupo social e do objeto de pesquisa que se pretende investigar - o que parece pertinente, considerando que aqui tratamos especificamente de um jogo que se desenrola na esfera do ordinário na vida dos seus jogadores, e não constitui necessariamente um evento específico ao qual devem se dedicar de forma separada do seu cotidiano (Huizinga, 2008).

Dito isso, podemos agora apresentar o objeto em questão e, em seguida, sob uma perspectiva autorreflexiva, comentar nossos apontamentos realizados durante a inserção no jogo em questão. Ressaltamos, não pretendemos aqui apresentar análises definitivas sobre a matéria, nem consideramos que as reflexões expostas correspondam à totalidade das apropriações possíveis do Ingress por parte dos jogadores - dada inclusive a concisão desse trabalho. Para que fosse possível registrar os acontecimentos e aspectos que nos chamaram a atenção durante a participação no jogo, utilizamos como registro anotações (tanto em papel quanto em aplicativos com essa função no próprio dispositivo móvel utilizado); também realizamos capturas de tela que foram anexadas às notas, sendo que algumas delas estão expostas adiante.

\section{O Ingress}

O Ingress é um jogo móvel locativo ${ }^{2}$ (Lemos, 2010) de realidade aumentada ${ }^{3}$, ou ainda um augmented reality game (ARG) que, uma vez instalado em dispositivos móveis digitais que possuem conexões à Internet via redes sem fio, permite que o jogador visualize em seu dispositivo um mapa das imediações onde ele se encontra, a partir da

\footnotetext{
${ }^{2}$ Lemos (2010) define jogos móveis locativos como aqueles "jogos urbanos que utilizam tecnologias e serviços baseados em localização nos quais o lugar é parte integrante das regras e ações do jogo".

${ }^{3}$ Realidade Aumentada é um conjunto de tecnologias e protocolos que permitem adicionar e visualizar imageticamente camadas de informação vinculadas ao espaço físico, através de equipamentos (telefones celulares, óculos especiais, capacetes) e da imbricação entre redes informacionais globais e a cidade.
} 
base de dados georrefenciada do Google $\mathrm{Maps}^{4}$, e sinais de geoposicionamento via satélite emitidos e recebidos pelo aparelho. Entretanto, diferentemente de outros sistemas de navegação espacial, o objetivo é especificamente a camada lúdica e informacional que lhe é adicionada: é possível identificar e capturar os pontos da energia Exotic Matter (Matéria Exótica, ou XM) espalhados pelo espaço e se movimentando à medida em que o jogador transita pelas ruas da cidade, bem como verificar itens disponíveis para aquisição - além de visualizar graficamente os portais, inclusive com a indicação de distância e rotas de deslocamento até eles (figura 1).
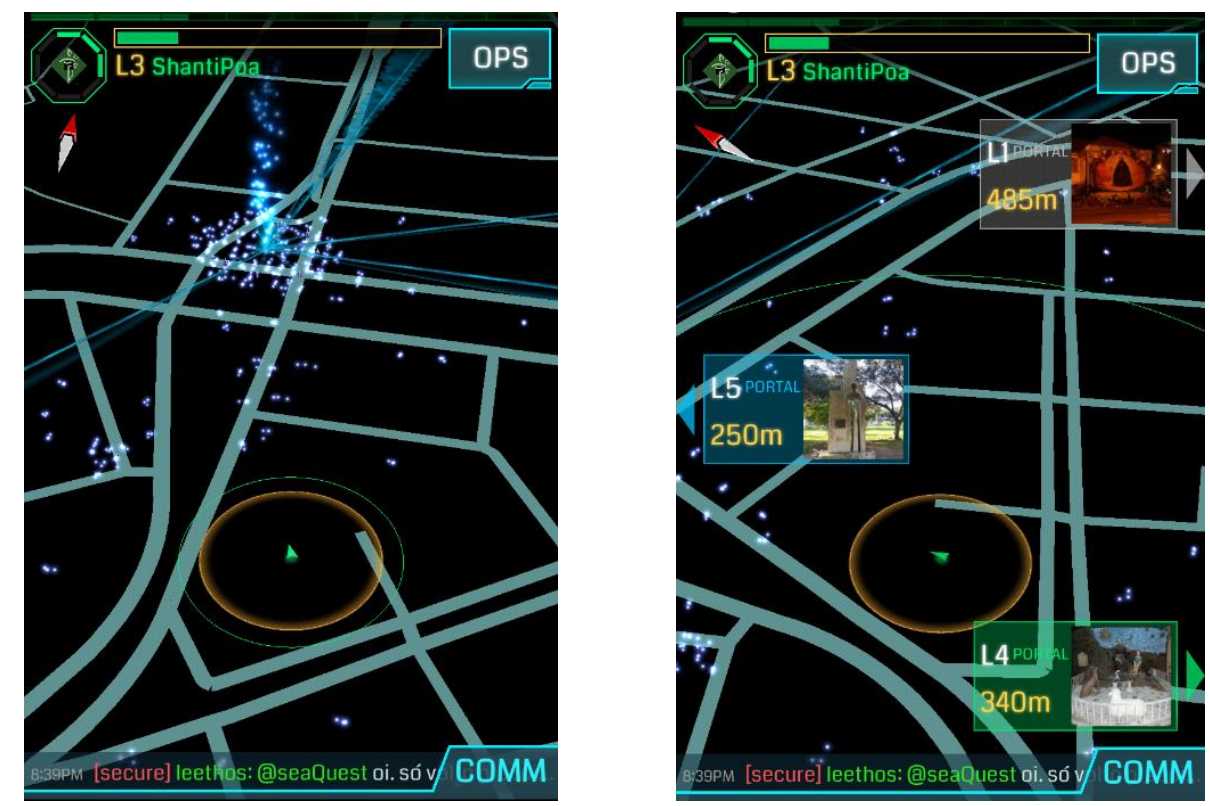

Figura 1: Tela inicial do jogo Ingress. Fonte: o autor (2014)

O sentido do jogo é em sua essência móvel, e convida os que dele participam a explorarem o espaço urbano das cidades em busca de portais, ou seja, locais nos quais a $X M$ emana - os quais são, em sua maioria, monumentos, praças, edifícios, pontos históricos e turísticos e outros pontos de grande circulação de pessoas, capturando em seus percursos fragmentos dessa energia espalhados aleatoriamente e adquirindo armas e outros elementos simbólicos do jogo. Cada um desses portais é de domínio de uma ou de outra facção, e o papel dos jogadores é percorrer esses locais e atacá-los, buscando a sua posse. Inclusive, através de uma funcionalidade onde é possível se comunicar

\footnotetext{
${ }^{4}$ http://maps.google.com.br/. Acesso em 26 jul. 2014
} 
secretamente com outros membros da mesma equipe, coordenar ataques coletivos simultâneos a um portal, exigindo assim um regime de copresença de vários jogadores.

Além disso, uma evidência de que o sentido do jogo se encontra justamente na exploração do espaço físico é que, para a progressão em níveis que variam de 1 a 8 , é necessário um número cada vez maior de pontos de experiência, adquiridos principalmente com o registro e a descoberta de portais novos - visitar e realizar hacking repetidamente nos mesmos portais torna um tanto demorada a progressão no jogo. Seja através de situações deliberadas - o jogador visitar um local unicamente objetivando uma ação de jogo - ou mesmo ocorrendo em ocasiões casuais de trajetos de ida e volta de locais nos quais o jogo não é o principal propósito (trabalho, estudo, situações de consumo, entre outras), parece-nos que nessas caminhadas pela cidade podem ser fornecidas novas experiências sensoriais e perceptivas através da sobreposição de uma camada informacional que, mesmo fictícia, altera as experiências do sujeito em relação ao espaço urbano. Ainda, importante acrescentar que é sine qua non a presença do jogador nas imediações dos portais: é impossível hackear, atacar, defender ou realizar qualquer ação remotamente nos mesmos, ou seja, à distância.

Uma pesquisa divulgada em $2013^{5}$, feita com 1.572 jogadores do Ingress revelou alguns dados interessantes que parecem confirmar a tendência do jogo em questão a estimular novas relações com o espaço e a cidade: $88 \%$ declararam que visitaram locais que nunca tinham ido nas suas próprias cidades a partir do uso no jogo. 93\% deles afirmaram ter passado a caminhar mais depois do início das atividades no jogo, e $24 \%$ passaram a andar mais de bibicleta. Um outro aspecto que merece destaque é o seu caráter social: $74 \%$ dos entrevistados afirmaram que conheceram pessoas por meio do jogo e $29 \%$ afirmaram ter feito novos amigos. Isso parece expor que, além de desempenhar um papel como mediadores das relações espaciais entre os jogadores e a cidade, o jogo funciona também como catalizador de interações sociais com propósitos muito específicos e que, talvez, não ocorrerriam entre os jogadores senão a partir do Ingress.

O mote principal do jogo se encontra se encontra na interseção entre redes digitais móveis e o espaço físico da cidade, conforme é demonstrado em vídeo promocional divulgado pelo laboratório responsável por prover de informações atualizadas e complexificar a cada dia a narrativa do jogo ${ }^{6}$. "O mundo real não é como parece",

\footnotetext{
${ }^{5} \mathrm{http} / / /$ simulacrum.cc/2013/01/23/the-demographics-of-ingress/. Acesso em 21 jan. 2014.

${ }^{6}$ https://www.youtube.com/watch?v=92rYjlxqypM. Acesso em 13 jul. 2014.
} 
afirmam categoricamente; obviamente, deve-se aceitar tal premissa para que o jogador adentre o enredo e participe efetivamente na construção narrativa lúdica. Não se joga “como se", recuperando Caillois (1990) - ou o jogador crê na veracidade do que está vivenciando naquele momento específico (o que não impede que ele saiba se tratar de ficção), ou nenhuma estratégia técnica, narrativa ou gráfica funcionará, por mais sofisticada ou elaborada que seja. Ao transformar cidadãos comuns em agentes secretos por meio do download e instalação do aplicativo Ingress em seu smartphone ou tablet, é necessário convencê-los a comprar a história do jogo, ou seja, absorvê-los na cosmologia lúdica que é instaurada.

Como dissemos, o jogo se fundamenta na dinâmica de competição entre duas equipes a partir da simulação de um conflito épico que ocorre pelas ruas da cidade dominadas pelas facções. Mas, para que uma equipe siga como dominante em uma região, é necessário que seus membros cooperem entre si, em processos de ajuda mútua visando atingir um determinado objetivo comum - seja ele destruir um ponto rival, manter um portal estratégico para a sua facção, ou ainda trocar informações, novidades, descobertas e outros conteúdos a respeito do andamento do jogo.

Durante a pesquisa para a elaboração desse trabalho, constatamos a existência de comunidades em sites de rede social (principalmente o Google $+^{7}$ ) e em serviços de trocas de mensagens instantâneas, como o Hangouts $^{8}$, e no aplicativo para dispositivos móveis WhatsApp ${ }^{9}$. Utilizados como ferramentas alternativas ao jogo, nesses espaços são discutidas estratégias de domínio de regiões dentro das cidades, de ataques simultâneos a portais inimigos, bem como de troca de informações sobre o andamento do jogo e das ações feitas. Ainda no tocante às dinâmicas de cooperação e conflito, percebemos também a existência de um hábito entre os jogadores - e que ficou evidente quando acompanhamos as conversas por meio dessas ferramentas de articulação e interação social entre eles -, que é a reunião planejada e coletiva em algum ponto da cidade com vistas ao ataque coletivo a um portal de nível elevado, visando destruí-lo - ação difícil de

\footnotetext{
${ }^{7}$ http://plus.google.com. Acesso em 15 jul. 2014.

${ }^{8}$ Hangouts é um serviço de troca de mensagens instantâneas multiplataforma do Google Inc., proprietária também do Google + e do Ingress, que pode ser utilizado tanto em sua versão web para computadores tradicionais quanto através de um aplicativo instalado em dispositivos móveis. Ele permite que pessoas conversem, inclusive com a formação de grupos nos quais vários usuários podem trocar mensagens instantaneamente. Disponível em https://www.google.com.br/hangouts/. Acesso em 15 jul. 2014.

${ }^{9}$ WhatsApp é um aplicativo gratuito de troca de mensagens multiplataforma para dispositivos móveis de propriedade do Facebook Inc.
} 
ser realizada de forma solitária. Capturamos também, durante a pesquisa, imagens relacionadas a esses eventos disponibilizadas em boletins oficiais, o Ingress Report, enviado via e-mail pela desenvolvedora do jogo para os seus participantes (fig. 2):

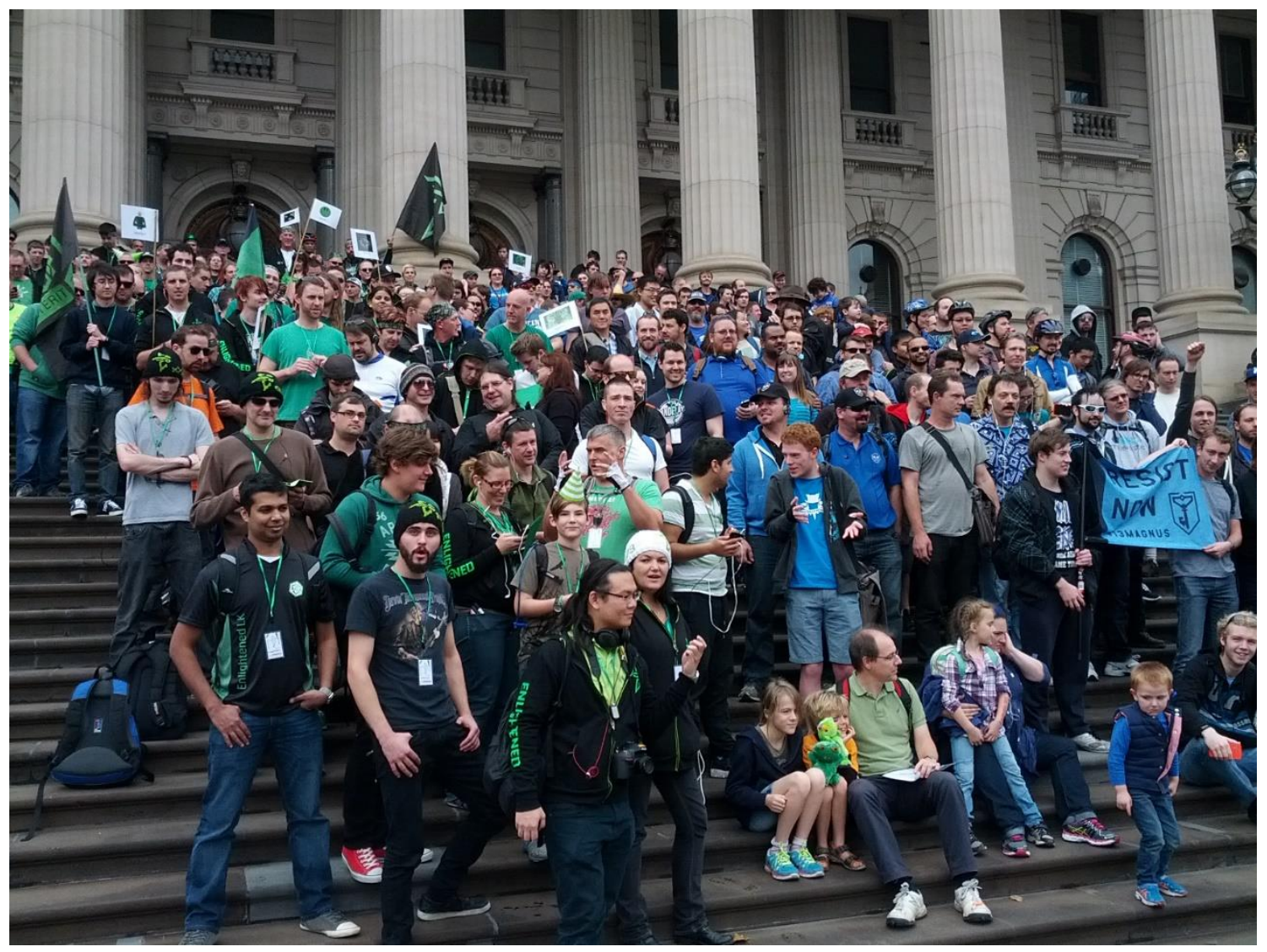

Fig. 2: grupo de jogadores reunidos em local público para encontro. Fonte: Decode Ingress (2014)

Há dentro do aplicativo do Ingress um campo no qual é possível se comunicar com outros jogadores: em um deles, todos os participantes têm acesso às mensagens, não importando a qual equipe pertençam; em outro, é permitida a conversa apenas entre os membros de uma mesma facção. É interessante observar também a existência de agentes duplos, que participam das duas equipes com usuários diferentes, mas que se engajam primordialmente em uma, utilizando a outra exclusivamente para obter informações privilegiadas. Durante a pesquisa para a elaboração deste trabalho, tomamos conhecimento de um grupo coletivo de jogadores no WhatsApp pertencente aos Iluminados na cidade de Porto Alegre - RS, visando especificamente tornar mais segura 
a troca de informações entre os membros da facção citada e articular ações coletivas em portais inimigos (fig. 3):

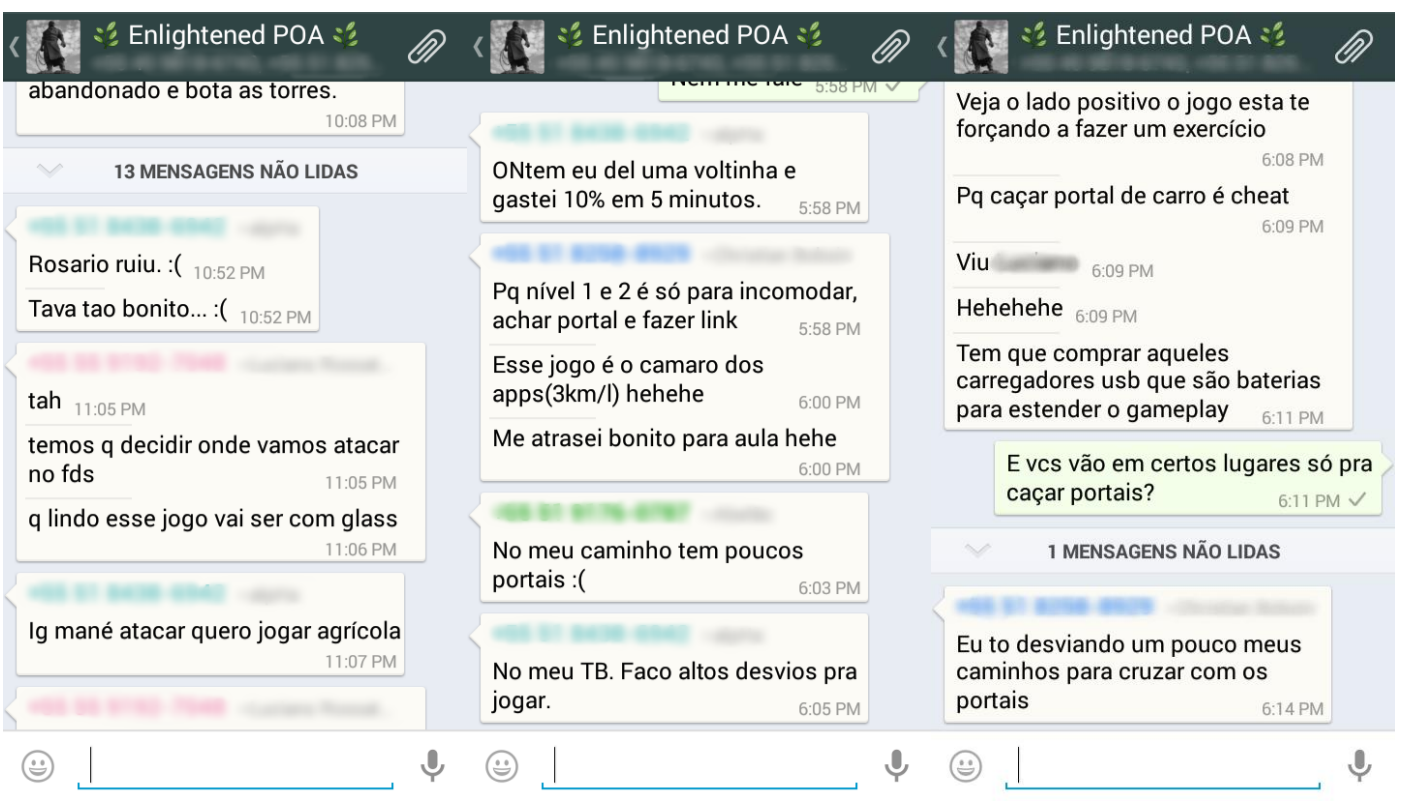

Fig. 3: grupo no WhatsApp de jogadores pertencentes aos Iluminados em Porto Alegre - RS.Fonte: o autor (2014)

Interessante observar como em diversos momentos da teoria de Simmel (1983), o termo jogo surge como vocábulo para designar as dinâmicas nas relações sociais entre os indivíduos, dada a própria imprevisibilidade que emana do conceito na perspectiva do sociólogo, e que parece convergir tal como o trabalhamos aqui. Convém recuperar que Caillois (1990) sugere a questão do desconhecimento do resultado final do jogo como um fator principal do fascínio que ele exerce entre os jogadores. Além disso, ao utilizar o conceito de jogo como designador das possibilidades interativas e das relações entre indivíduos em Simmel (1983), parece confirmada a ideia exposta previamente do caráter social do mesmo, lançando mão de tal termo para denotar sempre um encontro, estar junto com o outro.

Cabe ainda ressaltar a noção de competição para Simmel como uma forma pura de conduta humana. Já dissemos que a questão é intrínseca ao jogo em suas diversas manifestações, mesmo que não possua tal característica explícita ou que ela não seja o produto final do ato de jogar. Entendemos que existem modalidades de jogos que possuem a competição como força-motriz do funcionamento dos mesmos; entretanto, cremos que, ao considerarmos os mesmos sob a perspectiva de Simmel como forma básica de sociação entre os indivíduos, podemos entender a competição como elemento 
básico das relações humanas em sociedade. A partir de tal constatação, nos parece pertinente entender a competição como interação, ou seja, como uma

(...) forma de relação dos homens entre si; forma que pode envolver toda sorte de conteúdo, mas que, a despeito da grande variedade desses conteúdos, a forma mantém sua própria identidade e prova que pertence a um campo regulado segundo leis próprias e suscetíveis de abstração (1983: 66).

Sabemos que a cidade é, desde sempre, espaço de conflito, negociação, criação e destruição inventiva a partir das suas apropriações e usos previstos ou inesperados, a partir de uma pulsão da vida metropolitana, dando origem a modos de vida que Jacobs (2009: 13) descreve como sendo "fantasticamente dinâmicos". Nesse sentido, podemos inclusive pensar na transmutação do espaço sob um prisma lúdico como sendo a busca por um reencantamento do mundo weberiano, propiciado pelo jogo; a energia que, dentro da cosmologia do Ingress, emana do espaço público é de caráter fantástico, misterioso, mágico. Ela está e não está nos lugares de forma simultânea: ao mesmo tempo em que é presente e objeto de disputa por parte de jogadores, os cidadãos desavisados que transitam por aquele mesmo espaço sequer se dão conta de que, paralelamente, é travada uma batalha simbólica e física sobre aquele ponto.

As relações de conflito e cooperação, assim, servem como engatilhadores de transformações sociais, espaciais e simbólicas, através da habitação de um distinto contexto espacial e temporal que existe como possibilidade, imaginação e criação coletiva. $\mathrm{O}$ ordinário, assim, passa a ser extraordinário a partir de inesperadas formas de intervenção no espaço físico. Ou seja, como defende Certeau (1998: 178) uma rua não é a mesma para duas pessoas, ou mesmo para uma mesma pessoa em situações diferentes; ou seja, "o caminhante transforma em outra coisa cada significante espacial".

\section{Considerações Finais}

Reapropriar a cidade como fábula. Essa é a premissa do Ingress, jogo que tomamos como objeto de incursão nesse trabalho. Ao transitarem pela cidade em seus trajetos cotidianos e aparentemente de forma casual, os jogadores se apropriam do espaço físico, constroem relações que ultrapassam os vínculos formais ou esperados sobre aqueles lugares. Da mesma forma como a arte de rua, estilos de música e demais manifestações artísticas, os jogos que misturam o espaço físico com o imaterial, o on-line e o off-line, o 
comum e o fantástico, também expressam uma cultura urbana pulsante, cheia de vida, em cidades que são incessantemente desconstruídas, reconstruídas e ressimbolizadas através de seus usos criativos. Ou seja, “(...) uma cultura urbana [que] se expressa não só por suas convenções gestuais, de linguagens recorrentes, especializações profissionais de seus portadores, mas [que] se apresenta igualmente através de suas práticas ordinárias, saberes e tradições" (Rocha; ECkert, 2013c: 25).

Longe de esgotar as possibilidades de análise em relação a um objeto ainda tão recente e, ao mesmo tempo, tão fundamental para o homem - o jogo -, temos ciência que aqui buscamos apontar algumas questões que podem servir de embasamento para que possamos pensar o objeto em mais profundidade em momento posterior, haja vista a própria concisão desse trabalho. Tomando como horizonte também a compreensão da cidade como tessituras discursivas surgidas das práticas individuais e sociais em relação à mesma; ou seja, como sugere Magnani (1992), a paisagem urbana, composta pelas suas composições arquitetônicas, urbanísticas e sociais é o resultado das práticas, intervenções e modificações que a sua ocupação causa - o que também é corroborado por Certeau (1998). Nesse sentido e visando uma investigação mais profunda do nosso objeto, acreditamos que a antropologia urbana e a etnografia de rua se apresentam como poderosas fontes de diálogo com o campo da Comunicação.

\section{Referências}

BUYTENDIJK, U. F. J. J. . O jogo humano. In: GADAMER, H. G. e VOGLER, P. (Org.). Nova antropologia: o homem em sua existência biológica, social e cultural. São Paulo: EPU, v.4, 1977. CAILLOIS, Roger. Os jogos e os homens: a máscara e a vertigem. Lisboa: Cotovia, 1990.

CERTEAU, Michel de. A invenção do cotidiano: Artes de fazer. Petrópolis: Vozes, 1998.

DI FELICE, Massimo. Paisagens pós-urbanas: o fim da experiência urbana e as formas comunicativas do habitar. São Paulo: Annablume, 2009.

FRAGOSO, Suely; RECUERO, Raquel; AMARAL, Adriana. Métodos de pesquisa para internet. Porto Alegre: Sulinas, 2011.

GADAMER, Hans-Georg. Verdade e método. Petrópolis: Vozes, 1997.

HINE, Christine. Virtual ethnography. Londres: Sage, 2000.

HUIZINGA, Johan. Homo ludens: o jogo como elemento da cultura. São Paulo: Perspectiva, 2008.

JACOBS, Jane. Morte e vida de grandes cidades. São Paulo: Martins Fontes, 2009. 
KOZINETS, Robert V. Netnography: Doing etnography research online. Londres: Sage, 2010.

LEMOS, André. Cidade ciborgue. Revista transdisciplinar de Comunicação, Semiótica, Cultura. Brasília: PUC - SP 2004.

Jogos móveis locativos: Cibercultura, espaço urbano e mídia locativa. Revista USP, n. 86, p. 54-65, 2010.

MAFFESOLI, Michel. Sobre o nomadismo: vagabundagens pós-modernas. Rio de Janeiro: Record, 2001.

MAGNANI, José Guilherme Cantor. Da periferia ao centro: Pedaços e trajetos Revista de Antropologia v. 35, p. 191-203, 1992.

MCLUHAN, Marshall. Os meios de comunicação como extensão do homem. 4ed. São Paulo: Cultrix, 2007.

MONTOLA, Markus; STENROS, Jaakko; WAERN, Annika. Pervasive Games, theory and design: Experiences on the boundary between life and play. Burlington: Morgan Kaufmann, 2009.

ROCHA, Ana Luiza Carvalho da; ECKERT, Cornelia. Antropologia da e na cidade: Interpretações sobre as formas da vida urbana. Porto alegre: Marcavisual, 2013a.

Etnografia de e na rua: Estudo de antropologia urbana. In: ECKERT, C. e ROCHA, A.

L. C. D. (Org.). Etnografia de rua: Estudos de antropologia urbana. Porto Alegre: Editora da UFRGS, 2013b. p.p. 21-46.

Etnografia de rua: Estudos de antropologia urbana. Porto Alegre: Editora da UFRGS, $2013 c$

SANTAELLA, Lúcia. Linguagens líquidas na era da mobilidade. São Paulo: Paulus, 2007.

SIMMEL, Georg. Sociologia. São Paulo: Ática, 1983.

WEISER, Mark. The computer for the 21st century. Scientific American, v. 265, n. 03, 1991.

Recebido em: 30/09/2014

Aprovado em: 22/11/2014 